\title{
Diet with a combination of high protein and high total antioxidant capacity is strongly associated with low prevalence of frailty among old Japanese women: a multicenter cross-sectional study
}

Satomi Kobayashi ${ }^{1 *}$ (D) Hitomi Suga ${ }^{2}$, Satoshi Sasaki, ${ }^{1,2}$ and the Three-generation Study of Women on Diets and Health Study Group

\begin{abstract}
Background: The intake of protein and antioxidants has been inversely associated with frailty, individually. However, to our knowledge, no study has evaluated these associations in considering antioxidants or protein intakes as respective confounders. Further, the cooperative effect of dietary protein and antioxidants on frailty has not been investigated. Therefore, we examined the association of high protein and high dietary total antioxidant capacity (TAC) with frailty under the adjustment for dietary TAC or protein intake, respectively. The association between the combination of high dietary protein and high dietary TAC and frailty was also investigated.

Methods: A total of 2108 grandmothers or acquaintances of dietetic students aged 65 years and older participated in this cross-sectional multicenter study conducted in 85 dietetic schools in Japan. Dietary variables, including protein intake, and dietary TAC were estimated from a validated brief-type self-administered diet history questionnaire. Frailty was defined as a score of three or more points obtained from the following four components: slowness and weakness (two points), exhaustion, low physical activity, and unintentional weight loss.

Results: Median (interquartile range) age of the present subjects was 74 (71-78) years. Multivariate adjusted ORs $(95 \% \mathrm{Cls})$ for frailty in the highest compared to the lowest tertile were $0.66(0.49,0.87)$ for total protein intake $(P$ for trend $=0.003)$ and $0.51(0.37,0.69)$ for dietary TAC $(P$ for trend $<0.0001)$ after adjustment for dietary TAC or total protein intake, respectively. The OR of frailty for the group with both the highest tertiles of total protein intake and dietary TAC was markedly lower (multivariate adjusted OR [95\% Cls]: $0.27[0.16,0.44] ; P<0.0001$ ) compared to the group with the lowest tertile of protein intake and the lowest tertile of dietary TAC.

Conclusions: Both protein intake and dietary TAC were independently inversely associated with frailty among old Japanese women. Further, a diet with the combination of high dietary protein and high dietary TAC was strongly inversely associated with the prevalence of frailty in this population. To select food combinations that allow for an increase of both protein and antioxidants in diet according to the local food culture and dietary habits may be an effective strategy for frailty prevention.
\end{abstract}

Keywords: Protein, Total antioxidant capacity, Frailty, Brief-type self-administered diet history questionnaire, Old Japanese women

\footnotetext{
*Correspondence: satomikoba@m.u-tokyo.ac.jp

'Department of Social and Preventive Epidemiology, School of Public Health,

the University of Tokyo, 7-3-1 Hongo, Bunkyo-ku, Tokyo 113-0033, Japan

Full list of author information is available at the end of the article
} 


\section{Background}

Population aging is continuing worldwide [1]. People with frailty, a health status among older populations characterized by low physiological reserves and vulnerability to several stressors [2], are assumed to be increasing in the world, because the prevalence of frailty increases with age $[3,4]$. Frail individuals have higher risks of subsequent disability, falls, hospitalization, and death than those who are not frail [2, 5-7]. Therefore, the prevention of frailty is important for minimizing these adverse health outcomes and for meeting the challenge of successful aging in rapidly aging countries, including Japan [8].

Poor nutritional status is assumed to be one of the important modifiable risk factors for frailty [9-12]. Previous observational studies have suggested that adequate intakes of macronutrients and micronutrients may reduce the risk of frailty [9-12]. For example, some cross-sectional [13-15] and prospective [16, 17] studies have shown that higher protein intake was associated with lower risk of frailty. The intake of antioxidant nutrients, such as vitamin E and vitamin C [14] or resveratrol [18], and dietary total antioxidant capacity (TAC) [19] was also inversely associated with frailty. However, none of these studies considered other targeted dietary variables assumed to be associated with frailty as confounders. The independent effects of a high-protein or high-antioxidant diet on frailty with simultaneous consideration of each other in a statistical model have not been examined yet.

Since people do not consume single nutrients but instead meals containing a combination of foods with a wide range of nutrients, investigating the influences of nutrient combinations on frailty may be more useful than analyzing the influences of single nutrients when developing a strategy of frailty prevention. Unfortunately, previous studies have not identified effective nutrient combinations that prevent frailty $[9,11]$. The cooperative effect of dietary protein and antioxidants on frailty has also not been examined yet.

Further studies that identify the effect of single and combined dietary intake on frailty are needed in order to develop effective and general strategies for frailty prevention. Here, we investigated the independent association between protein intake or dietary TAC and frailty among old Japanese women under the adjustment for dietary TAC or protein intakes, respectively. Further, the effect of a diet combining high protein and high dietary TAC on frailty was also evaluated to investigate the cooperative association of protein and antioxidants to frailty.

\section{Methods}

\section{Procedure}

This cross-sectional study was based on data from the Three-generation Study of Women on Diets and Health.
A detailed description of the study design and survey procedure has been published elsewhere $[13,19]$. Briefly, two questionnaires for diet and lifestyle were distributed to a total of 7016 dietetic freshmen students in April 2011 or 2012. The students were also requested to directly distribute the questionnaires to their mothers and grandmothers or 65-to 89-year-old female acquaintances and invite them to join the study. The protocol of the study was approved by the Ethics Committee of the University of Tokyo Faculty of Medicine (approval number: 3249; approved on November 29, 2010). Written informed consent was obtained from all participants. The subjects for the present study were the participants of the old women for the grandmothers' generation.

\section{Dietary assessment}

Dietary habits during the preceding month were assessed using a previously validated, brief-type self-administered diet history questionnaire (BDHQ) designed to assess an individual's habitual dietary intake [20,21]. Details of the BDHQ's structure, method of calculating dietary intake, and validity for commonly studied food and nutrient intakes have been published elsewhere [20, 21]. Estimates of the daily intake for 58 foods, energy, and selected nutrients, including protein, were calculated based on the Standard Tables of Food Composition in Japan [22]. Protein from fish and shellfish, meat, eggs, and dairy products was included in animal protein. Protein from cereals, pulses, potatoes, confectionaries, fruits, vegetables, alcoholic beverages, and non-alcoholic beverages was included in plant protein. Pearson's correlation coefficients of protein intake between that from the 16-d dietary record and that from the BDHQ in 92 women aged 31-69 was 0.35 [21]. Dietary TAC was calculated using the answers of the BDHQ and the TAC value we assigned to each food item in the BDHQ [19]. To develop the TAC database for the BDHQ, we searched for analytical values by PubMed database. When the values could not be obtained, substituted values (analytical values of similar foods), or calculated values (calculated analytical values of ingredient food) was used. Dietary TAC was estimated based on intake and the TAC value of each food [19]. Although the validity of dietary TAC estimated from the BDHQ has not been evaluated, the previous validation study of the BDHQ among 92 adult women for foods and nutrients reported that Spearman's correlation coefficients for some food groups, which are the main contributors of dietary TAC [19], were 0.64 for green tea, 0.77 for coffee, 0.55 for total vegetables, and 0.41 for fruits [20] and Pearson's correlation coefficients for some antioxidant nutrients were 0.57 for $\beta$-carotene, 0.66 for vita$\min C$, and 0.48 for $\alpha$-tocopherol [21]. In the present study, we used the value assayed by oxygen radical 
absorbance capacity (ORAC) as the TAC value since ORAC value was the most strongly associated with frailty in our previous study [19]. Meanwhile, we confirmed the association between dietary TAC and frailty by using other dietary TAC value we previously evaluated, namely ferric reducing ability of plasma (FRAP), Trolox equivalent antioxidant capacity (TEAC), and total radical-trapping antioxidant parameter (TRAP) [19]. Although dietary supplement use was queried in the lifestyle questionnaire, intake from supplements was not included in the calculation for nutrient intakes and dietary TAC due to the lack of a reliable composition table of dietary supplements in Japan. The supplement use was treated as confounding factors.

\section{Frailty}

Although frailty was operationally defined by Fried et al. [2] to include the measures of walking speed for slowness and grip strength for weakness, we did not obtain these measures in our study, but rather used the modified definition developed by Woods et al. [5]. Frailty was assessed using the following four components: 1 ) slowness and weakness (physical functioning scale of the Japanese version short-form 36-item health survey [SF-36] < 75) [23-25]; 2) exhaustion (vitality scale of SF-36 $<55$ ); 3) low physical activity (those in the lowest quartile); and 4) unintentional weight loss (self-reported unintentional weight loss in the previous one year $>5 \%$ ). Physical activity was calculated as the average metabolic equivalent-hours, on the basis of the self-reported duration of five activities (walking, bicycling, standing, running, and high-intensity activities) and sleeping and sitting hours over the preceding month, and the metabolic equivalent (MET) value assigned to each activity [26].

Slowness and weakness was scored as two points, and the other components as one point each. Total frailty score was the sum of all available scores $(0-5)$, with those subjects with a total score $\geq 3$ defined as frail [5].

\section{Other variables}

Body mass index (BMI) was calculated as current body weight $(\mathrm{kg})$ divided by the square of body height $(\mathrm{m})$. Residential area was grouped into six regions (Hokkaido and Tohoku, Kanto, Hokuriku and Tokai, Kinki, Chugoku and Shikoku, and Kyushu) and also into three categories according to population size (city with a population $\geq 1$ million, city with a population $<1$ million, and town and village). The subject also reported whether she was living alone, as well as her marital status (single, married, widowed, or separated), education ( $\leq$ junior high school and others, high school, and $\geq$ college), current smoking status, alcohol drinking, dietary supplement use, and history of chronic diseases. A history of chronic disease, including stroke, myocardial infarction, hypertension, diabetes, and chronic rheumatism, with which the proportions of the subject were different between frail group and non-frail group, was considered as an indicator of past health status. Since the proportions of the subject with other diseases, i.e. any cancers and hepatic disease, were not different between these groups, we did not include these diseases as chronic disease. Depression symptoms were assessed using the Center for Epidemiologic Studies Depression (CES-D) scale $[27,28]$ incorporated in the lifestyle questionnaire, with subjects with a CES-D score $\geq 16$ considered to have depression symptoms.

\section{Statistical analysis}

All dietary variables were adjusted for energy by the residual method using a linear regression model [29] and the density method as a percentage of daily energy intake for energy-containing nutrients or per $1000 \mathrm{kcal}$ of daily energy intake for non-energy-containing nutrients, foods, and dietary TAC. The characteristics of the subjects with and without frailty were compared using Mann-Whitney signed-rank test for continuous variables or the chi-square test for categorical variables. We used the non-parametric test because the result of Kolmogorov-Smirnov test for normality showed that all continuous variables had non-normal distribution.

The subjects were divided into tertiles according to protein intake and dietary TAC adjusted by the residual method. Odds ratios (ORs) and 95\% confidence intervals (CIs) of each protein and dietary TAC for frailty were calculated by different logistic regression model after adjusting for potential confounding factors. The initial model was a crude model into which covariates were added using forward selection method. Final multivariate models used age (y, continuous), BMI $\left(\mathrm{kg} / \mathrm{m}^{2}\right.$, continuous), residential block (six blocks), size of residential area (three areas), living alone (yes or no), current smoking (yes or no), alcohol drinking (yes or no), dietary supplement use (yes or no), history of chronic disease (yes or no), depression symptoms (yes or no), and energy intake ( $\mathrm{kcal} / \mathrm{d}$, tertiles) as potential confounding factors. Other variables, namely survey year (2011 or 2012), marital status (four categories), and education (three categories), were not included in the models, because these variables had no influence on the relationship between dietary variables and frailty $(P>0.10)$. We further adjusted for other dietary variables (i.e., dietary TAC for total protein; plant protein and dietary TAC for animal protein; animal protein and dietary TAC for plant protein; and total, animal, and plant protein for dietary TAC [tertile]). In this examination, each dietary variable was input to the one model, e.g., to examine the association between total protein and frailty with the adjustment for 
dietary TAC, we input total protein intake and dietary TAC into the model, simultaneously. The subjects were further divided into nine $(3 \times 3)$ groups defined by the combination of total protein intake (tertile) and dietary TAC (tertile). Adjusted odds ratios of frailty for these nine groups were also calculated using the same model. The dietary intakes in three groups of the lowest tertile for both protein intake and dietary TAC (P1A1), intermediate tertile for them (P2A2) and highest tertile for them (P3A3) were compared by Kruskal-Wallis test. These dietary variables were selected to describe comprehensive dietary intake among the present subjects. An analysis using dietary variables adjusted by the density method was also conducted.

All statistical analyses were performed with SAS statistical software, version 9.4 (SAS Institute Inc., Cary, NC, USA). All reported $P$ values were two-tailed, with a $P$ value of $<0.05$ considered statistically significant.

\section{Results}

A total of 2332 women in the grandmothers' generation (33.2\%) answered both questionnaires. We excluded those subjects who lived in eastern Japan and answered questionnaires in $2011(n=47)$, because of the Great East Japan Earthquake in March 2011. We also excluded a subject $(n=1)$ in an institution because of standardization, where the response rate for participating home was extremely low (4\%) than all the other institutions (35-100\%). Further, we excluded subjects whose age, height, weight, or residential area was missing $(n=20)$; those aged $<65$ years $(n=65)$; and those with a reported energy intake less than half of the energy requirement for the lowest physical activity category according to the Dietary Reference Intakes for Japanese, $2010(<725 \mathrm{kcal} / \mathrm{d} ; n=14)$ [30] or those with an intake more than 1.5 times of the energy requirement for the highest physical activity category (>3300 kcal $/ \mathrm{d} ; n=32$ ). We further excluded those with Parkinson's disease $(n=8)$, chronic kidney disease $(n=13)$, those who were unable to walk ( $n=20$; to avoid misclassification of frailty), and those with missing information on the variables used for the purpose of multivariate analysis $(n=4)$. The final sample thus comprised 2108 women aged 65-94 years. The subject excluded from the present study was significantly younger, and had lower proportions of living alone and a history of chronic disease than the study population (data not shown).

Median age (interquartile range [IQR]) of the study population was 74 (71-78) years and median BMI was 22.5 (20.6-24.7) (Table 1). A total of 481 women (22.8\%) were classified as frail. Compared with the non-frail group, the frail group was significantly older, had a higher BMI and more current smokers, higher proportions of a history of chronic disease and depression symptoms, and fewer alcohol drinkers and supplement users. Median (IQR) intake (and contribution to energy values) of protein were $73.1(65.0-81.4) \mathrm{g} / \mathrm{d}$ (16.7 [14.7-18.8] \%) for total protein, 42.0 (33.7-51.8) g/d (9.5 [7.4-11.9] \%) for animal protein, and 30.3 $(27.7-33.2) \mathrm{g} / \mathrm{d}(7.0$ [6.4-7.6] \%) for plant protein (Table 2). Protein intake per body weight (BW) was $1.43(1.22-1.67) \mathrm{g} / \mathrm{kg} \mathrm{BW} / \mathrm{d}$. Median (IQR) (energyadjusted value) dietary TAC was 20.2 (15.7-25.0) mmol TE/d (11.7 [9.0-15.1] mmol TE/1000 kcal). The Spearman's correlation coefficients between proteins and dietary TAC were 0.07 for total protein, -0.03 for animal protein, and 0.24 for plant protein, and that between animal protein and plant protein was -0.34 (data not shown). Energy intake among the frail subjects was significantly lower than among the non-frail ones. Protein intake and dietary TAC in the frail group were significantly lower than those in the non-frail group. The median values of frail group to those of non-frail group were 96, 94, and 97\% for total protein, 93 and 92\% for animal protein, 99 and $99 \%$ for plant protein, and 87 and $89 \%$ for dietary TAC.

Total protein intake was significantly inversely associated with frailty $(P$ for trend $=0.001)$, and a similar association was observed in animal protein intake $(P$ for trend $=0.04)$ (Table 3). These associations were maintained after further adjustment for dietary TAC ( $P$ for trend $=0.003$ for total protein and 0.03 for animal protein). Meanwhile, no association was observed between the intake of plant protein and frailty ( $P$ for trend $=0.30$ ). Although a weak inverse association was observed in the second tertile in the adjustment for animal protein, further adjustment of dietary TAC attenuated the association. Dietary TAC was also significantly inversely associated with frailty in multivariate adjusted model ( $P$ for trend $<0.0001$ ). After further adjustment for intake of each protein, the association between dietary TAC and frailty were maintained (All $P$ for trend $<0.0001$ ). The associations between total protein and frailty in the adjustment for dietary TAC and between dietary TAC and frailty in the adjustment for total protein were examined by using one regression model. The multivariate adjusted ORs (95\% CIs) in the third tertile compared by the first tertile were 0.66 $(0.49,0.87)$ for total protein and $0.52(0.39,0.71)$ for dietary TAC. The association of dietary TAC was higher than that of total protein.

The subjects were divided nine groups based on the combination of the tertile of total protein intake and the tertile of dietary TAC, and the risk of frailty was predicted in these nine groups (Table 4). The group composed of the highest tertile for both total protein intake and dietary TAC (P3A3) had a markedly low prevalence of frailty. The multivariate adjusted OR (95\% CIs) for frailty in P3A3 was 0.27 
Table 1 Basic characteristics of 2108 old Japanese women categorized with and without frailty ${ }^{a}$

\begin{tabular}{|c|c|c|c|c|c|c|c|c|c|c|c|c|c|}
\hline \multirow{3}{*}{$\overline{\text { Age, years }}$} & \multicolumn{4}{|c|}{ Total $(n=2108)$} & \multirow{2}{*}{\multicolumn{4}{|c|}{$\frac{\text { No frailty }{ }^{\mathrm{b}}(n=1627)}{\text { Median, IQR or } \mathrm{n}(\%)}$}} & \multicolumn{4}{|c|}{ Frailty $^{\mathrm{b}}(n=481)$} & \multirow{3}{*}{$\begin{array}{l}P^{c} \\
<0.0001\end{array}$} \\
\hline & \multicolumn{4}{|c|}{ Median, IQR or n (\%) } & & & & & \multicolumn{4}{|c|}{ Median, IQR or n (\%) } & \\
\hline & 74 & 71 & - & 78 & 74 & 70 & - & 77 & 77 & 74 & - & 81 & \\
\hline Body height, $\mathrm{cm}$ & 150.0 & 147.0 & - & 154.0 & 150.2 & 147.7 & - & 154.0 & 150.0 & 145.0 & - & 153.0 & $<0.0001$ \\
\hline Body weight, kg & 51.0 & 46.0 & - & 56.0 & 51.0 & 46.1 & - & 56.0 & 51.0 & 45.0 & - & 57.0 & 0.71 \\
\hline Body mass index, $\mathrm{kg} / \mathrm{m}^{2}$ & 22.5 & 20.6 & - & 24.7 & 22.4 & 20.5 & - & 24.4 & 22.8 & 20.8 & - & 25.4 & 0.02 \\
\hline Residential block, n (\%) & & & & & & & & & & & & & 0.38 \\
\hline Hokkaido and Tohoku & \multicolumn{4}{|c|}{$193(9.2)$} & \multicolumn{4}{|c|}{$142(8.7)$} & \multicolumn{4}{|c|}{$51(10.6)$} & \\
\hline Kanto & \multicolumn{4}{|c|}{$526(25.0)$} & \multicolumn{4}{|c|}{$404(24.8)$} & \multicolumn{4}{|c|}{$122(25.4)$} & \\
\hline Hokuriku and Tokai & \multicolumn{4}{|c|}{$510(24.2)$} & \multicolumn{4}{|c|}{$410(25.2)$} & \multicolumn{4}{|c|}{$100(20.8)$} & \\
\hline Kinki & \multicolumn{4}{|c|}{$262(12.4)$} & \multicolumn{4}{|c|}{$199(12.2)$} & \multicolumn{4}{|c|}{$63(13.1)$} & \\
\hline Chugoku and Shikoku & \multicolumn{4}{|c|}{$342(16.2)$} & $265(1$ & & & & $77(16$ & & & & \\
\hline Kyushu & $275(1$ & & & & $207(1$ & & & & $68(14$ & & & & \\
\hline Size of residential area, n (\%) & & & & & & & & & & & & & 0.26 \\
\hline City with a population $\geq 1$ million & $274(1$ & & & & $204(1$ & & & & $70(14$ & & & & \\
\hline City with a population $<1$ million & 1598 & 75.8) & & & 1247 & 76.6) & & & $351(7$ & & & & \\
\hline Town and village & $236(1$ & & & & $176(1$ & & & & $60(12$ & & & & \\
\hline Living alone, n (\%) & & & & & & & & & & & & & 0.30 \\
\hline No & 1759 & 33.4) & & & 1365 & 33.9) & & & $394(8$ & & & & \\
\hline Yes & $349(1$ & & & & $262(1$ & & & & $87(18$ & & & & \\
\hline Marital status, n (\%) & & & & & & & & & & & & & $<0.0001$ \\
\hline Single & $4(0.2)$ & & & & $3(0.2)$ & & & & $1(0.2)$ & & & & \\
\hline Married & 1275 & 50.5) & & & 1035 & 53.6) & & & $240(4$ & & & & \\
\hline Widowed & $777(3$ & & & & $546(3$ & & & & $231(4$ & & & & \\
\hline Separated & $52(2.5$ & & & & $43(2$ & & & & $9(1.9)$ & & & & \\
\hline Education, n (\%) & & & & & & & & & & & & & 0.04 \\
\hline$\leq$ Junior high school and others & $977(4$ & & & & $732(4$ & & & & $245(5$ & & & & \\
\hline High school & $933(4$ & & & & $733(4$ & & & & $200(4$ & & & & \\
\hline$\geq$ Some college & $198(9$ & & & & $162(1$ & & & & $36(7.5$ & & & & \\
\hline Current smoking, n (\%) & & & & & & & & & & & & & 0.002 \\
\hline No & 2054 & 97.4) & & & 1595 & 8.0) & & & $459(9$ & & & & \\
\hline Yes & $54(2$. & & & & $32(2$. & & & & $22(4.6$ & & & & \\
\hline Alcohol drinking, n (\%) & & & & & & & & & & & & & $<0.0001$ \\
\hline No & 1695 & 80.4) & & & 1278 & 78.6) & & & $417(8$ & & & & \\
\hline Yes & $413(1$ & & & & $349(2$ & & & & $64(13$ & & & & \\
\hline Dietary supplement use, n (\%) & & & & & & & & & & & & & 0.0002 \\
\hline No & 1475 & 70.0) & & & 1106 & 58.0) & & & $369(7$ & & & & \\
\hline Yes & $633(3$ & & & & $521(3$ & & & & $112(2$ & & & & \\
\hline Physical activity, total metabolic equivalents-hours/d & 38.1 & 34.3 & - & 43.2 & 39.6 & 35.9 & & 44.1 & 32.9 & 30.9 & & 36.4 & $<0.0001$ \\
\hline History of chronic disease ${ }^{d}, \mathrm{n}(\%)$ & & & & & & & & & & & & & $<0.0001$ \\
\hline No & 1059 & $50.2)$ & & & $864(5$ & & & & $195(4$ & & & & \\
\hline Yes & 1049 & 49.8) & & & $763(4$ & & & & $286(5$ & & & & \\
\hline
\end{tabular}


Table 1 Basic characteristics of 2108 old Japanese women categorized with and without frailty ${ }^{a}$ (Continued)

\begin{tabular}{llll}
\hline Depression symptoms ${ }^{\mathrm{e}}, \mathrm{n}(\%)$ & & $<0.0001$ \\
No & $1617(76.7)$ & $1363(83.8)$ & $254(52.8)$ \\
Yes & $491(23.3)$ & $264(16.2)$ & $227(47.2)$ \\
\hline
\end{tabular}

IQR interquartile range

${ }^{a}$ Values are medians and interquartile ranges or numbers of subjects (\%)

${ }^{b}$ Frailty score $(0-5)$ was defined as the sum of poor physical function (two points), exhaustion (one point), low physical activity (one point), and unintentional weight loss (one point). A score of $\geq 3$ was classified as indicating frailty

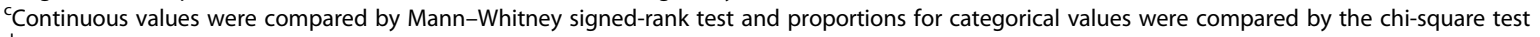

${ }^{\mathrm{d}}$ History of chronic disease was defined as having any of the following self-reported disease: stroke, myocardial infarction, hypertension, diabetes, or chronic rheumatism

e Depression symptoms were defined as a Center for Epidemiologic Studies Depression score $\geq 16$

$(0.16,0.44)(P=0.0001)$ compared with the reference group of the lowest tertile for both total protein intake and dietary TAC (P1A1).

We also examined the association between FRAP, TEAC, or TRAP and frailty. Similar results to Tables 3 and 4 were confirmed (data not shown).

Dietary intake and dietary TAC were described among the subject of P1A1, P2A2, and P3A3, respectively (Table 5). For many food intakes, e.g., pulses, potatoes, fruits, vegetables, fish and shellfish, meats, eggs, and dairy products, positive associations were observed in the order of P1A1, P2A2, and P3A3. Meanwhile, the negative associations were obtained for rice, confectionaries, and soft drinks. The intakes of almost all the nutrients examined and dietary TAC were increasing according to increasing of protein intake and dietary TAC. Only the carbohydrate intake was inversely associated with the increasing of protein intake and dietary TAC among all nutrients.

All the results shown in Tables 3,4 and 5 were obtained using dietary variables adjusted by the residual method. Similar results were observed for the density method (data not shown).

\section{Discussion}

In the present study, a higher intake of total and animal protein and dietary TAC were independently associated with a lower prevalence of frailty among old Japanese women. Further, the prevalence of frailty was markedly low in the subjects who consumed a diet with both high total protein and high dietary TAC. Such individuals had a significantly greater intake of pulses, potatoes, fruits, vegetables, fish and shellfish, meats, eggs, and dairy products and a lower intake of rice, confectionaries, and soft drinks than did those with both low total protein intake and low dietary TAC. To our knowledge, this is the first study to investigate the association of protein intake and dietary TAC with frailty, not only independently but also cooperatively.

Japanese government recommends daily total protein intake for old generation aged $\geq 70$ years of $0.85 \mathrm{~g} / \mathrm{kg} \mathrm{BW}$ [30]. However, the present study showed that total protein intake was $1.45 \mathrm{~g} / \mathrm{kg} \mathrm{BW} / \mathrm{d}$ for non-frail group. Even in the frail group, the respective value was $1.40 \mathrm{~g} / \mathrm{kg} \mathrm{BW} / \mathrm{d}$. Previous review studies showed that some study described the daily protein intake of $0.8 \mathrm{~g} / \mathrm{kg} \mathrm{BW} / \mathrm{d}$ is insufficient

Table 2 Energy and protein intakes and dietary TAC of 2108 old Japanese women categorized by no frailty and frailty ${ }^{a}$

\begin{tabular}{|c|c|c|c|c|c|c|c|c|c|c|c|c|c|}
\hline \multirow[b]{3}{*}{ Energy, kcal/d } & \multicolumn{4}{|c|}{ Total $(n=2108)$} & \multicolumn{4}{|c|}{ No frailty ${ }^{\mathrm{b}}(n=1627)$} & \multicolumn{4}{|c|}{ Frailty $^{\mathrm{b}}(n=481)$} & \multirow{3}{*}{$\begin{array}{l}P^{\complement} \\
<0.0001\end{array}$} \\
\hline & \multirow{2}{*}{$\begin{array}{l}\text { Median } \\
1693\end{array}$} & \multicolumn{3}{|l|}{ IQR } & \multirow{2}{*}{$\begin{array}{l}\text { Median } \\
1729\end{array}$} & \multicolumn{3}{|l|}{ IQR } & \multirow{2}{*}{$\begin{array}{l}\text { Median } \\
1589\end{array}$} & \multicolumn{3}{|l|}{$\mathrm{IQR}$} & \\
\hline & & 1396 & - & 2012 & & 1425 & - & 2042 & & 1317 & - & 1905 & \\
\hline Total protein, $\mathrm{g} / \mathrm{d}$ & 73.1 & 65.0 & - & 81.4 & 73.6 & 65.5 & - & 82.1 & 70.6 & 63.4 & - & 79.4 & 0.0001 \\
\hline Total protein, \% energy & 16.7 & 14.7 & - & 18.8 & 16.9 & 14.9 & - & 18.9 & 15.8 & 14.2 & - & 18.2 & $<0.0001$ \\
\hline Total protein, g/kg BW/d & 1.43 & 1.22 & - & 1.67 & 1.45 & 1.23 & - & 1.68 & 1.40 & 1.19 & - & 1.66 & 0.045 \\
\hline Animal protein, g/d & 42.0 & 33.7 & - & 51.8 & 42.7 & 34.1 & - & 52.3 & 39.8 & 32.9 & - & 49.6 & 0.004 \\
\hline Animal protein, \% energy & 9.5 & 7.4 & - & 11.9 & 9.7 & 7.6 & - & 12.0 & 8.9 & 7.0 & - & 11.3 & $<0.0001$ \\
\hline Plant protein, g/d & 30.3 & 27.7 & - & 33.2 & 30.3 & 27.9 & - & 33.3 & 29.9 & 27.1 & - & 32.8 & 0.02 \\
\hline Plant protein, \% energy & 7.0 & 6.4 & - & 7.6 & 7.0 & 6.4 & - & 7.6 & 6.9 & 6.2 & - & 7.7 & 0.10 \\
\hline Dietary TAC, mmol TE/d & 20.2 & 15.7 & - & 25.0 & 20.9 & 16.5 & - & 26.1 & 18.2 & 13.6 & - & 22.2 & $<0.0001$ \\
\hline Dietary TAC, mmol TE/1000 kcal & 11.7 & 9.0 & - & 15.1 & 12.0 & 9.4 & - & 15.4 & 10.7 & 7.8 & - & 13.9 & $<0.0001$ \\
\hline
\end{tabular}

BW Body wight, IQR interquartile range, TAC total antioxidant capacity, TE Trolox equivalent

${ }^{a}$ Values are medians and interquartile ranges

${ }^{b}$ Frailty score (0-5) was defined as the sum of poor physical function (two points), exhaustion (one point), low physical activity (one point), and unintentional weight loss (one point). A score of $\geq 3$ was classified as indicating frailty

${ }^{c}$ Values were compared by Mann-Whitney signed-rank test and proportions for categorical values were compared by the chi-square test 
Table 3 Multivariate adjusted odds ratios and 95\% confidence intervals for frailty compared to no frailty by tertile of dietary total antioxidant capacity and protein among 2108 old Japanese women ${ }^{\text {a }}$

\begin{tabular}{|c|c|c|c|c|}
\hline & T1 (Lowest) $(n=702)$ & T2 (Intermediate) $(n=703)$ & T3 (Highest) $(n=703)$ & $P$ for trend \\
\hline Total protein ${ }^{b}, g / d$ & $\leq 67.6$ & $67.6-78.3$ & $>78.3$ & \\
\hline Frailty ${ }^{c}, \%$ & 28.5 & 20.8 & 19.2 & \\
\hline Model $1^{d}$ & 1.00 (ref) & $0.61(0.46,0.80)$ & $0.64(0.48,0.84)$ & 0.001 \\
\hline Model $1^{\mathrm{e}}+$ dietary TAC & 1.00 (ref) & $0.62(0.46,0.82)$ & $0.66(0.49,0.87)$ & 0.003 \\
\hline Animal protein ${ }^{b}, g / d$ & $\leq 36.9$ & $36.9-48.4$ & $>48.4$ & \\
\hline Frailty ${ }^{c}, \%$ & 25.9 & 22.3 & 20.2 & \\
\hline Model $1^{\mathrm{e}}$ & 1.00 (ref) & $0.78(0.59,1.03)$ & $0.75(0.57,1.00)$ & 0.04 \\
\hline Model $1^{e}+$ dietary TAC $^{f}$ & 1.00 (ref) & $0.76(0.57,1.01)$ & $0.75(0.56,0.99)$ & 0.04 \\
\hline Model $1^{e}+$ plant protein ${ }^{f}$ & 1.00 (ref) & $0.75(0.57,1.00)$ & $0.68(0.51,0.92)$ & 0.01 \\
\hline Model $1^{e}+$ plant protein + dietary TAC $^{f}$ & 1.00 (ref) & $0.75(0.56,1.00)$ & $0.71(0.53,0.96)$ & 0.03 \\
\hline Plant protein ${ }^{\mathrm{b}}, \mathrm{g} / \mathrm{d}$ & $\leq 28.6$ & $28.6-32.0$ & $>32.0$ & \\
\hline Frailty $^{c}, \%$ & 25.6 & 21.3 & 21.5 & \\
\hline Model $1^{\mathrm{e}}$ & 1.00 (ref) & $0.78(0.59,1.03)$ & $0.86(0.65,1.14)$ & 0.30 \\
\hline Model $1^{\mathrm{e}}+$ dietary TAC & 1.00 (ref) & $0.82(0.62,1.09)$ & $0.99(0.74,1.33)$ & 0.91 \\
\hline Model $1^{\mathrm{e}}+$ animal protein ${ }^{\mathrm{f}}$ & 1.00 (ref) & $0.72(0.54,0.97)$ & $0.76(0.57,1.03)$ & 0.08 \\
\hline Model $1^{\mathrm{e}}+$ animal protein + dietary $\operatorname{TAC}^{f}$ & 1.00 (ref) & $0.77(0.58,1.03)$ & $0.89(0.65,1.21)$ & 0.42 \\
\hline Dietary TAC ${ }^{b}, \mathrm{mmol} T \mathrm{TE} / \mathrm{d}$ & $\leq 17.3$ & $17.3-23.1$ & $>23.1$ & \\
\hline Frailty ${ }^{c}, \%$ & 30.6 & 23.6 & 14.2 & \\
\hline Model $1^{\mathrm{e}}$ & 1.00 (ref) & $0.80(0.61,1.04)$ & $0.51(0.38,0.69)$ & $<0.0001$ \\
\hline Model $1^{\mathrm{e}}+$ total protein $^{\mathrm{f}}$ & 1.00 (ref) & $0.82(0.63,1.08)$ & $0.52(0.39,0.71)$ & $<0.0001$ \\
\hline Model $1^{\mathrm{e}}+$ animal protein ${ }^{\mathrm{f}}$ & 1.00 (ref) & $0.80(0.61,1.05)$ & $0.51(0.38,0.68)$ & $<0.0001$ \\
\hline Model $1^{\mathrm{e}}+$ plant protein ${ }^{\mathrm{f}}$ & 1.00 (ref) & $0.79(0.60,1.04)$ & $0.51(0.37,0.69)$ & $<0.0001$ \\
\hline
\end{tabular}

$\mathrm{Cl}$ confidence interval, OR odds ratio, ref reference, TAC total antioxidant capacity, TE Trolox equivalent

avalues are ORs $(95 \% \mathrm{Cls})$, unless otherwise indicated

${ }^{b}$ Protein intakes and dietary TAC were energy-adjusted according to the residual method

${ }^{c}$ Frailty score $(0-5)$ was defined as the sum of poor physical function (two points), exhaustion (one point), low physical activity (one point), and unintentional weight loss (one point). A score $\geq 3$ were classified as frailty

${ }^{\mathrm{e}}$ Adjusted for age (y, continuous), body mass index (kg/m2, continuous), residential block (Hokkaido and Tohoku, Kanto, Hokuriku and Tokai, Kinki, Chugoku and Shikoku, or Kyushu), size of residential area (city with a population $\geq 1$ million, city with a population $<1$ million, or town and village), living alone (yes or no), current smoking (yes or no), alcohol drinking (yes or no), dietary supplement use (yes or no), history of chronic disease (any of stroke, myocardial infarction, hypertension, diabetes, or chronic rheumatism; yes or no), depression symptoms (yes or no), and energy intake (kcal/d, tertiles)

${ }^{f}$ Further adjusted for total protein ( $\mathrm{g} / \mathrm{d}$, tertiles), animal protein $(\mathrm{g} / \mathrm{d}$, tertiles), plant protein ( $\mathrm{g} / \mathrm{d}$, tertiles), or dietary TAC (mmol/TE, tertiles)

for the maintenance of muscle mass and proposed 1.0-1.5

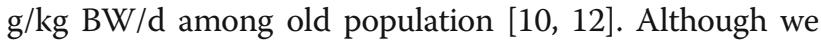
cannot adequately discuss the appropriate amount of protein intake in this study due to the limited validity of the $\mathrm{BDHQ}$, the amount of protein required to maintain muscle mass for old population might be higher than the present recommendation in Japan.

Median (IQR) dietary TAC among our subjects was 20.2 (15.7-25.0) mmol TE/d. Our previous study showed that median (IQR) dietary TAC among young Japanese women estimated by the comprehensive diet history questionnaire, on which the BDHQ was based for development, was 16.8 (12.4-24.1) mmol TE/d [31]. Although these values could not be compared directly, dietary TAC among the present participants might be higher than that of young Japanese women in the previous study.
Although the essential biological mechanism that causes frailty has never been adequately explained, hypotheses have proposed that the loss of muscle mass may be one of the causes of frailty $[9-12,32]$ and that sufficient dietary protein intake was required to maintain muscle mass and function $[10,12]$. The inverse association of dietary protein with frailty in previous studies [14-17] may be caused by preventing loss of muscle mass or improving the synthesis of muscle protein. Meanwhile, inflammation and oxidative stress, which also cause the reduction of muscle protein synthesis and promotion of muscle proteolysis, may play an important role in the development of frailty [11, 33, 34]. The inverse association between the intake of antioxidant nutrients and frailty in previous studies $[14,18]$ may be explained by the restriction of inflammation. Our results showed that both protein intake and dietary TAC were 
Table 4 Multivariate adjusted odds ratios and 95\% confidence intervals for frailty compared to no frailty based on a combination of total protein and dietary total antioxidant capacity among 2108 old Japanese women ${ }^{a}$

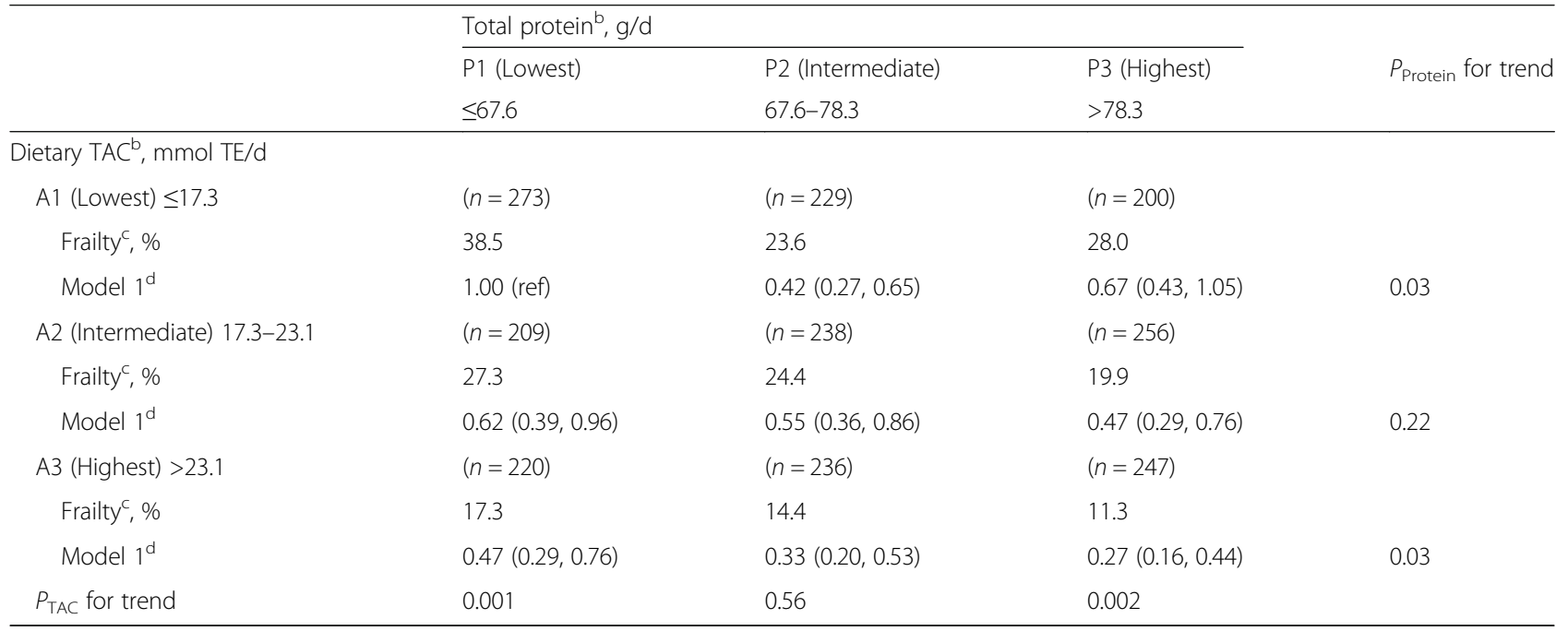

CI confidence interval, $O R$ odds ratio, ref reference, TAC total antioxidant capacity, TE Trolox equivalent

${ }^{\mathrm{a} V}$ alues are ORs $(95 \% \mathrm{Cls})$, unless otherwise indicated

${ }^{\mathrm{b}}$ Protein intake and dietary TAC were energy-adjusted according to the residual method

'Frailty score (0-5) was defined as the sum of poor physical function (two points), exhaustion (one point), low physical activity (one point), and unintentional weight loss (one point). A score of $\geq 3$ indicated frailty

${ }^{\mathrm{d} A d j u s t e d ~ f o r ~ a g e ~(~} \mathrm{y}$, continuous), body mass index ( $\mathrm{kg} / \mathrm{m}^{2}$, continuous), residential block (Hokkaido and Tohoku, Kanto, Hokuriku and Tokai, Kinki, Chugoku and Shikoku, or Kyushu), size of residential area (city with a population $\geq 1$ million, city with a population $<1$ million, or town and village), living alone (yes or no), current smoking (yes or no), alcohol drinking (yes or no), dietary supplement use (yes or no), history of chronic disease (any of stroke, myocardial infarction, hypertension, diabetes, or chronic rheumatism; yes or no), depression symptoms (yes or no), and energy intake (kcal/d, continuous)

inversely associated with frailty. These associations were consistent in the previous studies [14-18], and observed independently they may suggest that dietary protein and antioxidant activity individually prevent frailty by maintaining muscle mass and function.

Plant protein was not associated with frailty in our present study, albeit the association was observed in our previous study [13]. Although these studies were conducted using the same dataset, the previous study used quintiles instead of tertiles to categorize dietary intake leading more extreme group. This different methodological approach may cause different result. Our additional investigation using bisection, quartile, and quintile showed that, in only the quintile, plant protein was associated with frailty (data not shown). These different results may indicate that the effect of plant protein on frailty is relatively weak. The weak inverse association between plant protein and frailty in the adjusted model using animal protein was attenuated after further adjustment of dietary TAC. Many food sources of plant protein, e.g. pulses and vegetables, contributed to dietary TAC in this population $[13,19]$, and the correlation between dietary TAC and plant protein (0.24) was higher than that between dietary TAC and total protein $(0.07)$ or animal protein $(-0.03)$ in the present study. The effect of plant protein on frailty observed in the previous study [13] may have been caused by the antioxidant nutrients included in plant foods rather than the protein. In fact, our additional analysis showed that the significant inverse association between plant protein and frailty using quintile was disappeared after further adjustment for dietary TAC (data not shown).

In our study, the prevalence of frailty in the group with P3A3 was lowest among the groups. This association was more marked than those of single high protein and dietary TAC values, indicating that a diet containing both high protein and high antioxidant nutrients has the potential to prevent frailty more effectively than does high protein or high antioxidants solely. Although almost all of the combinations of the tertiles of total protein and dietary TAC were showed lower ORs than P1A1, only P3A1 showed non-significant association. The reason was unclear. This result might imply that the inverse association between protein and frailty was relatively weak under the low intake level of antioxidants. The previous studies showed that Mediterranean [35-37] and prudent dietary patterns [38] were associated with a low prevalence of frailty. This association may be caused by an abundance of both protein and antioxidants derived from fruits, vegetables, whole cereals, and oily fish. Not only increasing the intake of protein or antioxidants individually, but also increasing both of them simultaneously may be effective for frailty prevention. 
Table 5 Comparison of dietary intakes and dietary total antioxidant capacity between the women of the lowest tertile (P1A1), the intermediate tertile (P2A2) and highest tertile (P3A3) for both protein intake and dietary total antioxidant capacity ${ }^{\mathrm{a}}$

\begin{tabular}{|c|c|c|c|c|c|c|c|c|c|c|c|c|c|}
\hline \multirow{3}{*}{ Energy intake, kcal/d } & \multicolumn{4}{|c|}{ P1A1 $(n=273)$} & \multicolumn{4}{|c|}{ P2A2 $(n=238)$} & \multicolumn{4}{|c|}{ P3A3 $(n=247)$} & \multirow[t]{2}{*}{$p^{\mathrm{b}}$} \\
\hline & \multirow{2}{*}{$\begin{array}{l}\text { Median } \\
1709\end{array}$} & \multicolumn{3}{|l|}{ IQR } & \multirow{2}{*}{$\begin{array}{l}\text { Median } \\
1575\end{array}$} & \multicolumn{3}{|l|}{ IQR } & \multirow{2}{*}{$\begin{array}{l}\text { Median } \\
1700\end{array}$} & \multicolumn{3}{|l|}{ IQR } & \\
\hline & & 1423 & - & 2077 & & 1297 & - & 1905 & & 1405 & - & 2032 & 0.004 \\
\hline \multicolumn{14}{|l|}{ Food intake ${ }^{c}, g / d$} \\
\hline Rice & 368.7 & 292.7 & - & 423.5 & 277.4 & 227.4 & - & 353.4 & 207.0 & 147.0 & - & 256.0 & $<0.0001$ \\
\hline Noodles & 43.3 & 26.3 & - & 70.9 & 48.1 & 32.8 & - & 67.0 & 43.9 & 23.3 & - & 75.5 & 0.25 \\
\hline Bread & 27.0 & 15.0 & - & 54.1 & 27.3 & 12.4 & - & 58.7 & 27.3 & 12.8 & - & 56.5 & 0.64 \\
\hline Pulses & 58.1 & 39.7 & - & 74.7 & 77.6 & 57.2 & - & 108.0 & 102.2 & 71.2 & - & 123.1 & $<0.0001$ \\
\hline Potatoes & 40.4 & 25.7 & - & 66.9 & 50.1 & 32.0 & - & 76.4 & 57.8 & 40.2 & - & 97.8 & $<0.0001$ \\
\hline Confectioneries & 65.0 & 45.8 & - & 95.7 & 56.8 & 39.4 & - & 79.6 & 43.1 & 23.5 & - & 62.8 & $<0.0001$ \\
\hline Fruits & 65.5 & 40.2 & - & 113.8 & 97.9 & 65.8 & - & 142.3 & 127.6 & 79.1 & - & 186.8 & $<0.0001$ \\
\hline Total vegetables & 227.1 & 172.7 & - & 288.8 & 289.8 & 239.4 & - & 360.2 & 404.7 & 297.0 & - & 511.0 & $<0.0001$ \\
\hline Green tea & 170.9 & 41.6 & - & 380.0 & 428.3 & 369.6 & - & 607.0 & 562.2 & 379.6 & - & 609.4 & $<0.0001$ \\
\hline Black and oolong tea & 9.1 & -3.2 & - & 23.7 & 14.7 & 3.0 & - & 41.0 & 25.6 & 5.4 & - & 117.0 & $<0.0001$ \\
\hline Coffee & 21.3 & 1.9 & - & 117.6 & 59.5 & 14.0 & - & 148.5 & 157.0 & 105.0 & - & 365.7 & $<0.0001$ \\
\hline Soft drinks & 7.9 & -2.2 & - & 21.6 & 7.6 & -1.0 & - & 16.1 & 4.5 & -4.6 & - & 15.7 & 0.03 \\
\hline Fish and shellfish & 68.6 & 49.8 & - & 83.9 & 95.7 & 80.2 & - & 111.3 & 142.3 & 113.5 & - & 178.0 & $<0.0001$ \\
\hline Meats & 41.5 & 28.3 & - & 55.5 & 57.7 & 43.5 & - & 75.4 & 63.7 & 43.6 & - & 83.4 & $<0.0001$ \\
\hline Eggs & 32.1 & 21.7 & - & 48.2 & 37.1 & 26.3 & - & 54.6 & 45.8 & 29.6 & - & 65.7 & $<0.0001$ \\
\hline Dairy products & 103.4 & 37.5 & - & 153.0 & 128.9 & 69.7 & - & 173.5 & 155.8 & 91.2 & - & 199.0 & $<0.0001$ \\
\hline \multicolumn{14}{|l|}{ Nutrient intake ${ }^{c}$} \\
\hline Protein, g/d & 61.6 & 56.8 & - & 64.8 & 73.1 & 70.1 & - & 75.5 & 86.8 & 82.1 & - & 93.4 & $<0.0001$ \\
\hline Animal protein, $\mathrm{g} / \mathrm{d}$ & 31.6 & 26.2 & - & 36.1 & 42.0 & 38.9 & - & 45.4 & 56.4 & 50.8 & - & 61.9 & $<0.0001$ \\
\hline Plant protein, g/d & 29.6 & 27.7 & - & 31.6 & 30.3 & 28.0 & - & 33.3 & 31.1 & 28.5 & - & 33.9 & $<0.0001$ \\
\hline Fat, g/d & 44.2 & 38.9 & - & 49.9 & 50.5 & 45.4 & - & 55.5 & 55.0 & 48.6 & - & 61.1 & $<0.0001$ \\
\hline Marine origin n-3 polyunsaturated fat ${ }^{d}, g / d$ & 0.80 & 0.60 & - & 1.02 & 1.13 & 0.92 & - & 1.37 & 1.63 & 1.31 & - & 2.09 & $<0.0001$ \\
\hline Carbohydrate, g/d & 267 & 254 & - & 280 & 243 & 230 & - & 254 & 219 & 204 & - & 234 & $<0.0001$ \\
\hline Total dietary fiber, $\mathrm{g} / \mathrm{d}$ & 11.7 & 9.7 & - & 13.2 & 13.3 & 11.9 & - & 15.3 & 16.4 & 14.0 & - & 19.3 & $<0.0001$ \\
\hline$\beta$-carotene, $\mu \mathrm{g} / \mathrm{d}$ & 2882 & 2100 & - & 3902 & 3861 & 2992 & - & 5242 & 5246 & 3948 & - & 7704 & $<0.0001$ \\
\hline Vitamin $D, \mu g / d$ & 12.0 & 8.8 & - & 14.9 & 17.9 & 15.1 & - & 21.1 & 28.2 & 21.4 & - & 34.9 & $<0.0001$ \\
\hline Vitamin C, mg/d & 104 & 82 & - & 132 & 148 & 123 & - & 177 & 188 & 158 & - & 225 & $<0.0001$ \\
\hline Sodium, mg/d & 3872 & 3427 & - & 4278 & 4269 & 3900 & - & 4658 & 4981 & 4525 & - & 5465 & $<0.0001$ \\
\hline Potassium, mg/d & 2129 & 1871 & - & 2465 & 2754 & 2526 & - & 3051 & 3564 & 3194 & - & 4005 & $<0.0001$ \\
\hline Calcium, mg/d & 476 & 393 & - & 562 & 623 & 539 & - & 691 & 820 & 708 & - & 951 & $<0.0001$ \\
\hline Magnesium, mg/d & 219 & 198 & - & 236 & 266 & 253 & - & 292 & 342 & 312 & - & 378 & $<0.0001$ \\
\hline Iron, mg/d & 7.0 & 6.2 & - & 7.7 & 8.9 & 8.1 & - & 9.6 & 10.9 & 9.8 & - & 12.1 & $<0.0001$ \\
\hline Dietary $\mathrm{TAC}^{\mathrm{C}}, \mathrm{mmol} \mathrm{TE} / \mathrm{d}$ & 13.0 & 10.0 & & 15.3 & 20.1 & 18.9 & & 21.7 & 27.5 & 24.9 & & 31.8 & $<0.0001$ \\
\hline
\end{tabular}

$I Q R$ interquartile range, $P 1 A 1$ the lowest tertile for both total protein intake and dietary TAC group, $P 2 A 2$ the intermediate tertile for both total protein intake and dietary TAC group, P3A3 the highest tertile for both total protein intake and dietary TAC group, SD standard deviation, TAC total antioxidant capacity, TE Trolox equivalent

aalues are median and interquartile range

${ }^{b}$ Values were compared by Kruskal-Wallis test

c Energy-adjustment was performed according to the residual method

d Sum of eicosapentaenoic acid, docosapentaenoic acid, and docosahexaenoic acid

The present subjects in the P3A3 group had higher intake of pulses, potatoes, fruits, vegetables, fish and shellfish, meats, eggs, and dairy products and lower intakes of rice, confectionaries, and soft drinks than did those in the P1A1 group. The P3A3 subjects ate more of almost all the nutrients, except for carbohydrates, than 
did P1A1 subjects. Avoiding confectionaries or soft drinks and eating more fruits, vegetables, pulses, and fish and shellfish may be an effective dietary strategy for preventing frailty in the present population. Drinking green tea or coffee, which are the main contributors of dietary TAC in old Japanese women [19], instead of soft drinks, may be another way to prevent frailty. Appropriate food selections to increase the intake of protein and dietary TAC, based on food culture and dietary habits of target populations, may be important in frailty prevention.

The strength of our present study was our ability to examine the relation of protein intake and dietary TAC with frailty in a large number of old women using multicenter epidemiological data. The subjects lived over a wide geographical range of Japan and had various dietary and lifestyle habits. Additionally, the dietary questionnaire used has been validated [20, 21].

Several limitations of this study also warrant mention. First, dietary TAC was only moderately associated with plasma TAC measurements in previous studies [39, 40], and the method of evaluating the total antioxidant function in vivo is controversial [41]. However, several studies have demonstrated that the consumption of antioxidant-rich foods increased plasma TAC immediately after ingestion [42]. Furthermore, previous studies showed that dietary TAC was inversely associated with inflammatory molecules [43, 44]. Although the validity of dietary TAC estimated by the BDHQ has not been examined, dietary TAC estimated by a comprehensive diet history questionnaire, from which the BDHQ was developed, was also inversely associated with a serum inflammatory marker in our previous study [31]. These results may suggest that dietary TAC is a useful tool for assessing antioxidant intake and antioxidant activities in vivo $[41,45]$. Second, we used the score of the physical functioning scale of the SF-36 as a surrogate for walking speed and grip strength. However, all the criteria we used to define frailty were very similar to those proposed by Woods et al. [5], who showed that the physical functioning scale dichotomized at the 25th percentile was strongly associated with poor walking speed and moderately associated with poor grip strength, and maintained that their definition predicted outcomes as well as did Fried's definition [5]. These results may indicate the appropriateness of the criteria we used. Third, the BDHQ was a self-reported diet history questionnaire and are subject to both random and systematic measurement errors as all the other self-reported dietary assessment methods. To minimize the effect of misreporting, we excluded the subject reporting low or high energy intake and we used energy-adjusted values. Fourth, because reliable food composition table for dietary supplements could not be obtained in Japan, we could not consider the intake of dietary supplements in calculating nutrient intake and dietary TAC. However, we used the variable for dietary supplement use (yes or no) as confounders. Fifth, the present study was conducted under a cross-sectional design, which prevents the investigation of a causal effect of protein intake or dietary TAC on frailty. Therefore, we tried to minimize the effect of reverse causality by excluding subjects assumed to be under restricted protein intake (chronic kidney disease) or who had a disability (Parkinson's disease or those who were unable to walk), and also by calculating ORs adjusted for the history of chronic disease. The proportion of the subjects with these diseases is assumed to be underestimated because of self-reported, which is a further limitation of this study. Meanwhile, we examined the food source of protein among the subjects categorized by no frailty and frailty. The contribution of fish was significantly lower for frailty (29\%) than for no frailty (30\%) and the contribution of animal food was significantly lower (57\% vs 58\%) and plant food was higher (44\% vs $42 \%$ ) for frailty than for no frailty. These differences were small and the contributions of meat, dairy products, and eggs were not significantly different between the groups. Frail participants might not avoid eating to meat and similar food source of protein was obtained between frail and non-frail group, may indicate that there might be no problem of reverse causality for the cause of masticatory problems. Sixth, almost all subjects in the present study were grandmothers of selected dietetic students, and not a random sample of old Japanese women. Not all Japanese adolescents enter college or university (enrollment ratio: 57\%) [46], and the grandmothers of students who do so might accordingly have a relatively high social and economic status. Further, the nutrition interest of their grandchildren might influence their dietary habits. Thus, our results cannot be readily extrapolated to the general old Japanese population. Finally, although we attempted to adjust for a wide range of potential confounding variables, we were unable to rule out residual confoundings. Additionally, we should have excluded subjects with poor cognitive function because poor cognition is related to frailty [47] and might be associated with dietary TAC [48]. Since our selfreported questionnaires did not examine cognitive function, we could not exclude subjects with poor cognition. However, the study subjects answered the questionnaires themselves, which implies sufficient cognitive function to do so. Meanwhile, cognitive problems could also lead to unreliable answers to the questionnaires.

\section{Conclusions}

We found that total protein intake and dietary TAC was independently inversely associated with frailty in old 
Japanese women. The diet with the combination of high total protein and high dietary TAC was markedly associated with a low prevalence of frailty. Eating fruits, vegetables, pulses, and fish and shellfish and drinking green tea and coffee, instead of confectionaries and soft drinks, may be an effective strategy for frailty prevention among the Japanese population. In other populations, other food combinations that allow for an increase of both protein and antioxidants in their diet can be selected based on the local food culture and dietary habits. Further studies are needed to develop effective dietary strategies for the intervention of frailty prevention.

\begin{abstract}
Abbreviations
BDHQ: Brief-type self-administered diet history questionnaire; BMI: Body mass index; BW: Body weight; Cl: Confidence interval; FRAP: Ferric reducing ability of plasma; IQR: Interquartile range; MET: Metabolic equivalent; OR: Odds ratio; ORAC: Oxygen radical absorbance capacity; P1A1: The lowest tertile for both total protein intake and dietary total antioxidant capacity; P2A2: The intermediate tertile for both total protein intake and dietary total antioxidant capacity; P3A3: The highest tertile for both total protein intake and dietary total antioxidant capacity; SF-36: Short-form 36-item health survey; TAC: Total antioxidant capacity; TE: Trolox equivalent; TEAC: Trolox equivalent antioxidant capacity; TRAP: Total radical-trapping antioxidant parameter
\end{abstract}

\section{Acknowledgments}

The authors thank the members of the Three-generation Study of Women on Diets and Health Study Group as co-authors. All the members are listed in the following study: High protein intake is associated with low prevalence of frailty among old Japanese women: a multicenter cross-sectional study. Nutr J 2013; 12: 164.

\section{Funding}

This study was supported by JSPS KAKENHI Grant Number 22240077 from the Japan Society for the Promotion of Science.

\section{Availability of data and materials}

The datasets generated and/or analyzed during the current study are available from the corresponding author on reasonable request.

\section{Authors' contributions}

SK formulated the hypothesis, conducted the study, analyzed and interpreted the data, and wrote the paper. HS contributed to the conduct of the research and assisted the analysis. SS was responsible for designing and conducting the study and contributed to the writing and editing of the paper. All authors contributed to the final version of the manuscript.

\section{Competing interest}

The authors declare that they have no competing interest.

\section{Consent for publication}

Not applicable.

\section{Ethics approval and consent to participate}

This study was approved by the Ethics Committee of the University of Tokyo Faculty of Medicine (approval number: 3249; approved on November 29, 2010) and conducted according to the guidelines laid down in the Declaration of Helsinki. Written informed consent was obtained from all participants.

\section{Publisher's Note}

Springer Nature remains neutral with regard to jurisdictional claims in published maps and institutional affiliations.

\section{Author details}

${ }^{1}$ Department of Social and Preventive Epidemiology, School of Public Health, the University of Tokyo, 7-3-1 Hongo, Bunkyo-ku, Tokyo 113-0033, Japan.
${ }^{2}$ Department of Social and Preventive Epidemiology, Graduate School of Medicine, the University of Tokyo, Tokyo, Japan.

Received: 8 December 2016 Accepted: 4 May 2017

Published online: 12 May 2017

\section{References}

1. National Institute on Aging, National Institutes of Health, US Department of Health and Human Services. Global health and ageing. Geneva: WHO; 2011. http://www.who.int/ageing/publications/global_health/en/. Accessed 22 Aug 2016.

2. Fried LP, Tangen CM, Walston J, Newman AB, Hirsch C, Gottdiener J, Seeman T, Tracy R, Kop WJ, Burke G, McBurnie MA. Frailty in older adults: evidence for a phenotype. J Gerontol A Biol Sci Med Sci. 2001;56:M146-56.

3. Collard RM, Boter $\mathrm{H}$, Schoevers RA, Oude Voshaar RC. Prevalence of frailty in community-dwelling older persons: a systematic review. J Am Geriatr Soc. 2012;60:1487-92.

4. World Health Organization. World report on ageing and health. Geneva: WHO press; 2015. http://www.who.int/ageing/publications/world-report2015/en/. Accessed 22 Aug 2016

5. Woods NF, LaCroix AZ, Gray SL, Aragaki A, Cochrane BB, Brunner RL, Masaki $K$, Murray A, Newman AB. Frailty: emergence and consequences in women aged 65 and older in the Women's Health Initiative Observational Study. J Am Geriatr Soc. 2005:53:1321-30.

6. Abizanda P, Romero L, Sanchez Jurado PM, Martinez Reig M, Gomez Arnedo $\mathrm{L}$, Alfonso SA. Frailty and mortality, disability and mobility loss in a Spanish cohort of older adults: the FRADEA study. Maturitas. 2013;74:54-60.

7. Kojima G. Frailty as a predictor of hospitalisation among communitydwelling older people: a systematic review and meta-analysis. J Epidemiol Community Health. 2016;70:722-9.

8. National Institute of Population and Social Security Research. Population Projects for Japan, 2011-2060. Tokyo: National Institute of Population and Social Security Research; 2012 (in Japanese).

9. Goisser S, Guyonnet S, Volkert D. The Role of Nutrition in Frailty: An Overview. J Frailty Aging. 2016:5:74-7.

10. Bonnefoy M, Berrut G, Lesourd B, Ferry M, Gilbert T, Guerin O, Hanon O, Jeandel C, Paillaud E, Raynaud-Simon A, Ruault G, Rolland Y. Frailty and nutrition: searching for evidence. J Nutr Health Aging. 2015;19:250-7.

11. Kaiser MJ, Bandinelli S, Lunenfeld B. The nutritional pattern of frailty Proceedings from the 5th Italian Congress of Endocrinology of Aging, Parma, Italy, 27-28 March 2009. Aging Male. 2009;12:87-94.

12. Artaza-Artabe I, Saez-Lopez P, Sanchez-Hernandez N, Fernandez-Gutierrez N, Malafarina $V$. The relationship between nutrition and frailty: Effects of protein intake, nutritional supplementation, vitamin D and exercise on muscle metabolism in the elderly. A systematic review. Maturitas 2016 (Epublication ahead of print).

13. Kobayashi S, Asakura K, Suga H, Sasaki S. High protein intake is associated with low prevalence of frailty among old Japanese women: a multicenter cross-sectional study. Nutr J. 2013;12:164.

14. Bartali B, Frongillo EA, Bandinelli S, Lauretani F, Semba RD, Fried LP, Ferrucc L. Low nutrient intake is an essential component of frailty in older persons. J Gerontol A Biol Sci Med Sci. 2006;61:589-93.

15. Bollwein J, Diekmann R, Kaiser MJ, Bauer JM, Uter W, Sieber CC, Volkert D. Distribution but not amount of protein intake is associated with frailty: a cross-sectional investigation in the region of Nurnberg. Nutr J. 2013;12:109.

16. Beasley JM, Lacroix AZ, Neuhouser ML, Huang Y, Tinker L, Woods N, Michael $Y$, Curb JD, Prentice RL. Protein intake and incident frailty in the Women's Health Initiative Observational Study. J Am Geriatr Soc. 2010;58:1063-71.

17. Sandoval-Insausti H, Perez-Tasigchana RF, Lopez-Garcia E, Garcia-Esquinas E, Rodriguez-Artalejo F, Guallar-Castillon P. Macronutrients Intake and Incident Frailty in Older Adults: A Prospective Cohort Study. J Gerontol A Biol Sci Med Sci. 2016 (Epublication ahead of print).

18. Rabassa M, Zamora-Ros R, Urpi-Sarda M, Bandinelli S, Ferrucci L, AndresLacueva C, Cherubini A. Association of habitual dietary resveratrol exposure with the development of frailty in older age: the Invecchiare in Chianti study. Am J Clin Nutr. 2015;102:1534-42.

19. Kobayashi S, Asakura K, Suga H, Sasaki S. Inverse association between dietary habits with high total antioxidant capacity and prevalence of frailty among elderly Japanese women: a multicenter cross-sectional study. J Nutr Health Aging. 2014;18:827-39. 
20. Kobayashi S, Murakami K, Sasaki S, Okubo H, Hirota N, Notsu A, Fukui M, Date C. Comparison of relative validity of food group intakes estimated by comprehensive and brief-type self-administered diet history questionnaires against $16 \mathrm{~d}$ dietary records in Japanese adults. Public Health Nutr. 2011:14:1200-11.

21. Kobayashi S, Honda S, Murakami K, Sasaki S, Okubo H, Hirota N, Notsu A, Fukui $\mathrm{M}$, Date $\mathrm{C}$. Both comprehensive and brief self-administered diet history questionnaires satisfactorily rank nutrient intakes in Japanese adults. J Epidemiol. 2012;22:151-9.

22. Science and Technology Agency. Standard Tables of Food Composition in Japan, 2010. Tokyo: Ministry of Education, Culture, Sports, Science and Technology; 2010. in Japanese.

23. Fukuhara S, Bito S, Green J, Hsiao A, Kurokawa K. Translation, adaptation, and validation of the SF-36 Health Survey for use in Japan. J Clin Epidemiol. 1998;51:1037-44

24. Fukuhara S, Ware Jr JE, Kosinski M, Wada S, Gandek B. Psychometric and clinical tests of validity of the Japanese SF-36 Health Survey. J Clin Epidemiol. 1998;51:1045-53.

25. Fukuhara S, Suzukamo Y. Manual of SF-36v2 Japanese version. Institute for Health Outcomes \& Process Evaluation Research: Kyoto; 2004 (in Japanese).

26. Ainsworth BE, Haskell WL, Herrmann SD, Meckes N, Bassett Jr DR, Tudor Locke C, Greer JL, Vezina J, Whitt Glover MC, Leon AS. 2011 compendium of physical activities: a second update of codes and MET values. Med Sci Sports Exerc. 2011;43:1575-81.

27. Wada K, Tanaka K, Theriault G, Satoh T, Mimura M, Miyaoka H, Aizawa Y. Validity of the Center for Epidemiologic Studies Depression Scale as a screening instrument of major depressive disorder among Japanese workers. Am J Ind Med. 2007;50:8-12.

28. Radloff LS. The CES-D scale: a self-report depression scale for research in the general population. Appl Psychol Meas. 1977;1:385-401.

29. Willett W, Stampfer MJ. Total energy intake: implications for epidemiologic analyses. Am J Epidemiol. 1986;124:17-27.

30. Ministry of Health, Labour, and Welfare. Dietary Reference Intakes for Japanese, 2010. Tokyo: Ministry of Health and Welfare; 2009. in Japanese.

31. Kobayashi S, Murakami K, Sasaki S, Uenishi K, Yamasaki M, Hayabuchi H, Goda T, Oka J, Baba K, Ohki K, Watanabe R, Sugiyamama Y. Dietary total antioxidant capacity from different assays in relation to serum C-reactive protein among young Japanese women. Nutr J. 2012;11:91.

32. Evans WJ, Paolisso G, Abbatecola AM, Corsonello A, Bustacchini S, Strollo F, Lattanzio F. Frailty and muscle metabolism dysregulation in the elderly. Biogerontology. 2010;11:527-36.

33. Mulero J, Zafrilla P, Martinez CA. Oxidative stress, frailty and cognitive decline. J Nutr Health Aging. 2011;15:756-60.

34. Li H, Manwani B, Leng SX. Frailty, inflammation, and immunity. Aging Dis. 2011;2:466-73.

35. Talegawkar SA, Bandinelli S, Bandeen Roche K, Chen P, Milaneschi Y, Tanaka T, Semba RD, Guralnik JM, Ferrucci L. A higher adherence to a mediterranean-style diet is inversely associated with the development of frailty in community-dwelling elderly men and women. J Nutr. 2012; 42:2161-6.

36. Bollwein J, Diekmann R, Kaiser MJ, Bauer JM, Uter W, Sieber CC, Volkert D. Dietary quality is related to frailty in community-dwelling older adults. J Gerontol A Biol Sci Med Sci. 2013;68:483-9.

37. Leon-Munoz LM, Guallar-Castillon P, Lopez-Garcia E, Rodriguez-Artalejo F. Mediterranean diet and risk of frailty in community-dwelling older adults. J Am Med Dir Assoc. 2014;15:899-903.

38. Leon-Munoz LM, Garcia-Esquinas E, Lopez-Garcia E, Banegas JR, RodriguezArtalejo F. Major dietary patterns and risk of frailty in older adults: a prospective cohort study. BMC Med. 2015;13:11.

39. Pellegrini N, Salvatore S, Valtuena S, Bedogni G, Porrini M, Pala V, Del Rio D, Sieri S, Miglio C, Krogh V, Zavaroni I, Brighenti F. Development and validation of a food frequency questionnaire for the assessment of dietary total antioxidant capacity. J Nutr. 2007;137:93-8.

40. Rautiainen S, Serafini M, Morgenstern R, Prior RL, Wolk A. The validity and reproducibility of food-frequency questionnaire-based total antioxidant capacity estimates in Swedish women. Am J Clin Nutr. 2008;87:1247-53.

41. Ghiselli A, Serafini M, Natella F, Scaccini C. Total antioxidant capacity as a tool to assess redox status: critical view and experimental data. Free Radic Biol Med. 2000;29:1106-14.

42. Serafini M, Del Rio D. Understanding the association between dietary antioxidants, redox status and disease: is the Total Antioxidant Capacity the right tool? Redox Rep. 2004;9:145-52.
43. Brighenti F, Valtuena S, Pellegrini N, Ardigo D, Del Rio D, Salvatore S, Piatti P, Serafini M, Zavaroni I. Total antioxidant capacity of the diet is inversely and independently related to plasma concentration of high-sensitivity C-reactive protein in adult Italian subjects. Br J Nutr. 2005;93:619-25.

44. Hermsdorff HH, Zulet MA, Puchau B, Martinez JA. Fruit and vegetable consumption and proinflammatory gene expression from peripheral blood mononuclear cells in young adults: a translational study. Nutr Metab (Lond) 2010;7:42.

45. Wang Y, Chun OK, Song WO. Plasma and dietary antioxidant status as cardiovascular disease risk factors: a review of human studies. Nutrients. 2013:5:2969-3004

46. Ministry of Education, Culture, Sports, Science and Technology. General Survey of Schools, 2015. Tokyo: Ministry of Education, Culture, Sports, Science and Technology; 2015. http://www.mext.go.jp/component/b_ menu/other/_icsFiles/afieldfile/2016/01/18/1365622_1_1.pdf (in Japanese). Accessed 22 Aug 2016.

47. Shimada H, Makizako H, Doi T, Yoshida D, Tsutsumimoto K, Anan Y, Uemura K, Ito T, Lee S, Park H, Suzuki T. Combined prevalence of frailty and mild cognitive impairment in a population of elderly Japanese people. J Am Med Dir Assoc. 2013;14:518-24.

48. Devore EE, Kang JH, Stampfer MJ, Grodstein F. Total antioxidant capacity of diet in relation to cognitive function and decline. Am J Clin Nutr. 2010;92: 1157-64.

\section{Submit your next manuscript to BioMed Central and we will help you at every step:}

- We accept pre-submission inquiries

- Our selector tool helps you to find the most relevant journal

- We provide round the clock customer support

- Convenient online submission

- Thorough peer review

- Inclusion in PubMed and all major indexing services

- Maximum visibility for your research

Submit your manuscript at www.biomedcentral.com/submit
Biomed Central 